Check for updates

Cite this: RSC Adv., 2018, 8, 26640

\title{
Relating alkaline stability to the structure of quaternary phosphonium cations $\uparrow$
}

\author{
Bingzi Zhang, $\dot{t}^{\mathrm{a}}$ Hai Long, (D) $\dot{t}^{\mathrm{b}}$ Robert B. Kaspar, ${ }^{\mathrm{a}}$ Junhua Wang, ${ }^{\mathrm{a}}$ Shuang Gu, ${ }^{\mathrm{c}}$ \\ Zhongbin Zhuang, (D) de Bryan Pivovar ${ }^{\mathrm{b}}$ and Yushan Yan (D)*ade
}

Received 21st April 2018

Accepted 5th July 2018

DOI: $10.1039 / c 8 \mathrm{ra03440k}$

rsc.li/rsc-advances

\begin{abstract}
Alkali-stable quaternary phosphonium (QP) is a type of cationic group for hydroxide exchange membranes (HEMs). To elucidate the relationship between structure and alkaline stability, we investigated the kinetics and degradation mechanism of a series of QP cations by both experiment and computation, and established a semi-empirical formula based on the Taft equation to directly estimate alkaline stability of QP cations from the ${ }^{31} \mathrm{P}$ NMR chemical shift $\delta$ and the steric substituent constant $E_{\mathrm{s}}$, facilitating the search for QP cations with improved alkaline stability.
\end{abstract}

\section{Introduction}

Fuel cells are one of the most promising candidates for nextgeneration vehicle power sources. ${ }^{1-3}$ Proton exchange membrane fuel cells (PEMFCs) are the leading technology in this field, but their commercialization has been hindered by the high cost and low durability of precious-metal catalysts. ${ }^{4}$ By contrast, by switching the working ion from a proton $\left(\mathrm{H}^{+}\right)$to hydroxide $\left(\mathrm{OH}^{-}\right)$, hydroxide exchange membrane fuel cells (HEMFCs) enable non-precious metals such as silver ${ }^{5,6}$ and nickel $^{6,7}$ as electrocatalysts and thus have the potential to solve the catalyst cost and durability problems.

A major problem of the hydroxide exchange membrane (HEM) and hydroxide exchange ionomer (HEI) is poor alkaline stability, resulting from $\mathrm{OH}^{-}$attack of cationic groups linked to the polymer backbone. ${ }^{8-14}$ For example, the most widely used cations are quaternary ammoniums (QAs), ${ }^{15-27}$ such as benzyl trimethylammonium (BTMA). ${ }^{21}$ Experiment has shown that $77 \%$ of BTMA degraded in $1 \mathrm{M}$ KOD $\mathrm{CD}_{3} \mathrm{OD} / \mathrm{D}_{2} \mathrm{O}(5 / 1 \mathrm{vol})$ solution after $480 \mathrm{~h}$ at $80{ }^{\circ} \mathrm{C}$ (the typical HEMFC operating temperature), corresponding to a degradation rate constant at $80^{\circ} \mathrm{C}\left(k_{80}\right)$ of $8.3 \times 10^{-7} \mathrm{M}^{-1} \mathrm{~s}^{-1} .^{28}$ Instability of cationic groups

\footnotetext{
${ }^{a}$ Department of Chemical and Biomolecular Engineering, University of Delaware, Newark, DE 19716, USA. E-mail: yanys@udel.edu

${ }^{b}$ National Renewable Energy Laboratory, MS ESIF302, 15013 Denver West Parkway, Golden, Colorado 80401, USA

'Department of Mechanical Engineering, Wichita State University, Wichita, KS 67260, USA

${ }^{d}$ State Key Lab of Organic-Inorganic Composites, Beijing University of Chemical Technology, Beijing 100029, China

${ }^{e}$ Beijing Advanced Innovation Center for Soft Matter Science and Engineering, Beijing University of Chemical Technology, Beijing 100029, China

$\dagger$ Electronic supplementary information (ESI) available: Experimental section and additional characterizations and analysis of data for the studied QP cations. See DOI: $10.1039 / \mathrm{c} 8 \mathrm{ra} 03440 \mathrm{k}$

$\ddagger$ These authors contribute equally.
}

in an alkaline environment has limited the practical application of HEMFCs. ${ }^{29}$ Stabler cations are needed.

Switching the central atom from nitrogen to phosphorus yields quaternary phosphoniums (QPs), which showed promising alkaline stability. Yan's group developed a stabilized QP, benzyl tris(2,4,6-trimethoxyphenyl)phosphonium (BTPP-(2,4,6$\mathrm{MeO})),{ }^{30-32}$ in which the nine methoxy groups provide strong electron donation and steric hindrance. BTPP-(2,4,6-MeO) was found to be twice as stable as BTMA. ${ }^{28}$ HEMs based on BTPP(2,4,6-MeO)-functionalized polysulfone (PSf-BTPP-(2,4,6-MeO)) exhibited decent hydroxide conductivity $\left(45 \mathrm{mS} \mathrm{cm}^{-1}\right.$ at 20 ${ }^{\circ} \mathrm{C}$ ) and improved alkaline stability compared to the typical commercial QA-based FAA membranes. ${ }^{31}$ The degradation mechanism study of BTPP-(2,4,6-MeO) in alkaline environment further showed that the major degradation pathway is ether hydrolysis of methoxy substituents instead of oxide formation. ${ }^{28}$ Accordingly, we replaced the methoxy groups with methyl groups and developed a superior QP cation, methyl tris(2,4,6trimethylphenyl)phosphonium (MTPP-(2,4,6-Me)). MTPP$(2,4,6-\mathrm{Me})$ showed excellent alkaline stability $(<20 \%$ degradation after $5000 \mathrm{~h}$ at $80{ }^{\circ} \mathrm{C}$ in $1 \mathrm{M} \mathrm{KOD} \mathrm{CD}_{3} \mathrm{OD} / \mathrm{D}_{2} \mathrm{O}(5 / 1 \mathrm{vol})$ solution; $k_{80}=1.3 \times 10^{-8} \mathrm{M}^{-1} \mathrm{~s}^{-1}$ ): 31 times that of BTPP$(2,4,6-\mathrm{MeO})\left(k_{80}=4.0 \times 10^{-7} \mathrm{M}^{-1} \mathrm{~s}^{-1}\right)$ and 64 times that of BTMA, making it one of the most stable cations for HEMs. ${ }^{28}$

In this work, to further elucidate the relationship between structure and alkaline stability, we investigated the kinetics and degradation mechanism of a series of QP cations by both experiment and computation. We identified transition state (TS) structures and computed the degradation reaction free energy barriers $\Delta G^{\neq}$for these cations by density functional theory (DFT), an approach that previously improved understanding of degradation of QA and imidazolium cations. ${ }^{33-35}$ Our computed $\Delta G^{\neq}$values show a good linear relationship with experimental values. From these results, we established a semiempirical formula based on the Taft equation to directly 

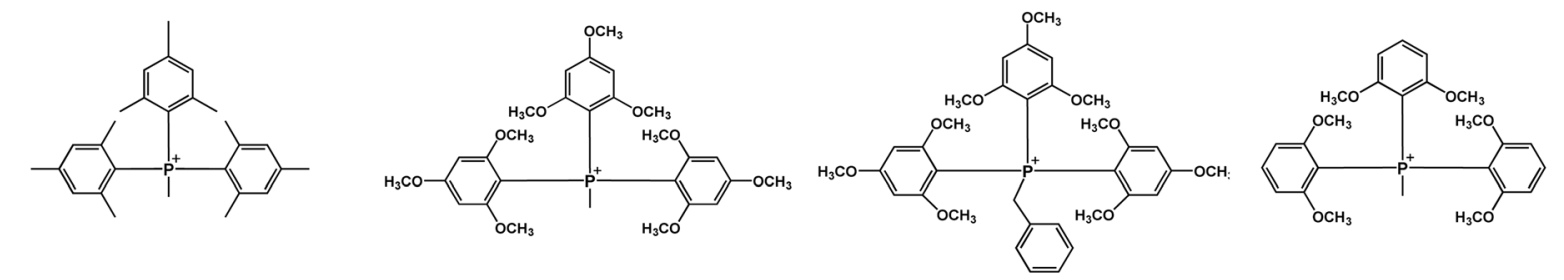

(1) МТРP-(2,4,6-Мe)

(2) MTPP-(2,4,6-MeO)

(3) ВТРP-(2,4,6-MeO)

(4) MTPP-(2,6-

MeO)
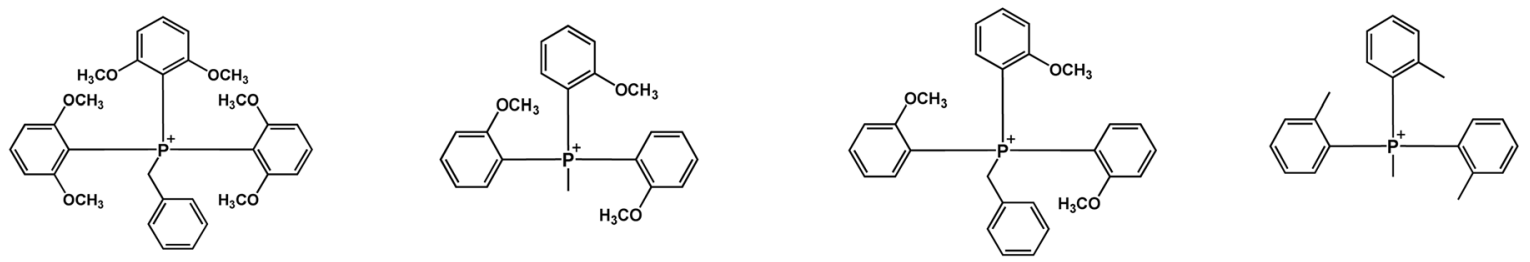

(5) ВТРP-(2,6-MeO)

(6) MTPP-(o-MeO)

(7) BTPP-(o-MeO)

(8) MTPP-(o-Me)<smiles>COc1ccc(C(C)(c2ccc(O)cc2)c2ccc(O)cc2)cc1</smiles>

(9) MTPP-(p-MeO)<smiles>COc1ccc(C(Cc2ccccc2)(c2ccc(C)cc2)c2ccc(C)cc2)cc1</smiles>

(10) ВТPР-(p-MeO)

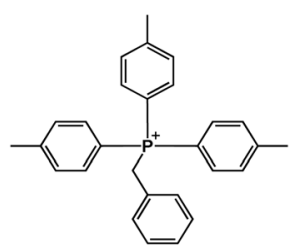

(11) BTPP-(p-Me)

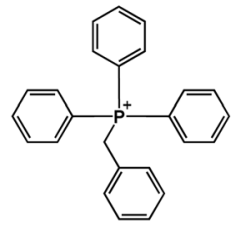

(12) ВТРP 
Table 2 Experimental measurements and DFT calculations at $80^{\circ} \mathrm{C}^{a}$

\begin{tabular}{|c|c|c|c|c|c|c|c|}
\hline QP & $\begin{array}{l}k_{80} \\
\left(\mathrm{M}^{-1} \mathrm{~s}^{-1}\right)\end{array}$ & $\begin{array}{l}k_{\mathrm{OF}} \\
\left(\mathrm{M}^{-1} \mathrm{~s}^{-1}\right)\end{array}$ & $\begin{array}{l}\Delta G_{\mathrm{OF}, \mathrm{EXP}}^{\neq} \\
\left(\mathrm{kcal} \mathrm{mol}^{-1}\right)\end{array}$ & $\begin{array}{l}\Delta G_{\mathrm{OF}, \mathrm{DFT}}^{\neq} \\
\left(\mathrm{kcal} \mathrm{mol}^{-1}\right)\end{array}$ & $\begin{array}{l}k_{\mathrm{EH}} \\
\left(\mathrm{M}^{-1} \mathrm{~s}^{-1}\right)\end{array}$ & $\begin{array}{l}\Delta G_{\mathrm{EH}, \mathrm{EXP}}^{\neq} \\
\left(\mathrm{kcal} \mathrm{mol}^{-1}\right)\end{array}$ & $\begin{array}{l}\Delta G_{\mathrm{EH}, \mathrm{DFT}}^{\neq} \\
\left(\mathrm{kcal} \mathrm{mol}^{-1}\right)\end{array}$ \\
\hline (1) & $1.3 \times 10^{-8}$ & $1.3 \times 10^{-8}$ & 31.0 & 28.0 & N/A & N/A & N/A \\
\hline (3) & $4.0 \times 10^{-7}$ & $\mathrm{~N} / \mathrm{M}$ & $\mathrm{N} / \mathrm{C}$ & 29.6 & $4.0 \times 10^{-7}$ & 28.6 & 26.8 \\
\hline (4) & $6.0 \times 10^{-7}$ & $5.0 \times 10^{-7}$ & 28.5 & 25.8 & $1.0 \times 10^{-7}$ & 29.6 & 27.2 \\
\hline (5) & $3.7 \times 10^{-7}$ & $1.9 \times 10^{-7}$ & 29.1 & 27.2 & $1.8 \times 10^{-7}$ & 29.2 & 25.8 \\
\hline (8) & $3.9 \times 10^{-4}$ & $3.9 \times 10^{-4}$ & 23.8 & 18.9 & N/A & N/A & $\mathrm{N} / \mathrm{A}$ \\
\hline (9) & $2.2 \times 10^{-4}$ & $2.2 \times 10^{-4}$ & 24.2 & 13.7 & $\mathrm{~N} / \mathrm{M}$ & $\mathrm{N} / \mathrm{C}$ & 26.1 \\
\hline (10) & $1.3 \times 10^{-3}$ & $1.3 \times 10^{-3}$ & 23.0 & 15.9 & $\mathrm{~N} / \mathrm{M}$ & $\mathrm{N} / \mathrm{C}$ & 26.6 \\
\hline (11) & $9.7 \times 10^{-2}$ & $9.7 \times 10^{-2}$ & 19.9 & 15.1 & $\mathrm{~N} / \mathrm{A}$ & N/A & $\mathrm{N} / \mathrm{A}$ \\
\hline (12) & $\mathrm{N} / \mathrm{M}$ & $\mathrm{N} / \mathrm{M}$ & $\mathrm{N} / \mathrm{C}$ & 14.7 & N/A & N/A & N/A \\
\hline
\end{tabular}

${ }^{a}$ N/A: it is not a viable pathway; N/M: it is a potential degradation pathway, but the value is not measurable due to limitation of experiment conditions; N/C: the value is not calculable from eqn (1).

estimate alkaline stability of QP cations from the ${ }^{31} \mathrm{P}$ NMR chemical shift $\delta$ and the steric substituent constant $E_{\mathrm{s}}$, providing insight on how to further improve stability.

\section{Experimental}

The QP cations studied in this work are shown in Table 1. The experimentally measured $k_{80}$ for each cation was obtained through alkaline stability tests. ${ }^{28,29}$ The details of QP synthesis, alkaline stability tests and NMR spectra are shown in the ESI, Fig. S1-S12. $\dagger \Delta G^{\neq}$was obtained by DFT calculation as we explained in detail elsewhere. ${ }^{8}$ In short, reactant and TS structures were optimized by the B3LYP ${ }^{36}$ method with Gaussian 09 (G09), with the $6-311++\mathrm{G}(2 \mathrm{~d}, \mathrm{p})$ basis set and polarizable continuum solvation model (PCM). Free energies at $80^{\circ} \mathrm{C}$ and 1 atm for the reactants and TS were then calculated based on the optimized structure. $\Delta G^{\neq}$was obtained by subtracting the free energy of the TS from the total free energies of the ground states of reactants (cation $\left.+\mathrm{OH}^{-}\right) .{ }^{8}$ For cations with different reaction sites for the same degradation pathway (e.g., the ether hydrolysis pathway can be on either $o-\mathrm{OCH}_{3}$ or $\left.p-\mathrm{OCH}_{3}\right), \Delta G^{\neq}$was calculated for all potential reaction sites, and the one with the lowest $\Delta G^{\neq}$value was reported.

\section{Results and discussion}

Under the test conditions, QP cations have two possible degradation pathways: oxide formation (nucleophilic addition, Fig. S13†), and ether hydrolysis of the methoxy substituents $\left(\mathrm{S}_{\mathrm{N}} 2\right.$, Fig. $\left.\mathrm{S} 14 \dagger\right)$. The experimentally measured rate constants for overall degradation $\left(k_{80}\right)$, oxide formation $\left(k_{\mathrm{OF}}\right)$, and ether hydrolysis $\left(k_{\mathrm{EH}}\right)$ for all the cations are shown in Table 2 . According to their degradation mechanisms, these cations can be divided into three categories (Table S1 $\dagger$ ): (i) chiefly oxide formation $\left(k_{80}=k_{\mathrm{OF}}\right)$; (ii) chiefly ether hydrolysis $\left(k_{80}=k_{\mathrm{EH}}\right)$; (iii) a mixture of both $\left(k_{80}=k_{\mathrm{OF}}+k_{\mathrm{EH}}\right)$. The first category includes some of the methoxy-substituted cations, for which oxide formation dominates ether hydrolysis rates (and thus $k_{80}=k_{\mathrm{OF}}$ is an excellent approximation), as well as all of the methylsubstituted cations. Cation (1)-(5) have $k_{80}$ values several orders of magnitude smaller than the other cations, indicating that occupying all of the ortho-positions can effectively prevent $\mathrm{OH}^{-}$from attacking the $\mathrm{P}$ center. Cation (1) shows the highest stability, because in addition to the large steric effect, the alkalistable methyl substituents eliminate the ether hydrolysis degradation pathway. The $k_{80}$ and $k_{\mathrm{OF}}$ of cation (12) are not measurable by this test due to its prohibitively rapid degradation even at room temperature.

The computational $\Delta G^{\neq}$values for both pathways $\left(\Delta G_{\mathrm{OF}, \mathrm{DFT}}^{\neq}\right.$and $\left.\Delta G_{\mathrm{EH}, \mathrm{DFT}}^{\neq}\right)$were compared with experimental values $\left(\Delta G_{\mathrm{OF}, \mathrm{EXP}}^{\neq}\right.$and $\left.\Delta G_{\mathrm{EH}, \mathrm{EXP}}^{\neq}\right)$(Table 2). The experimental $\Delta G^{\neq}$follows from the rate constant $k$ according to TS theory (eqn (1)):

$$
\Delta G^{\neq}=-R T \ln \left(k \frac{h}{k_{\mathrm{B}} T} \frac{p^{0}}{R T}\right)
$$

where $T$ is temperature; $h$, Planck constant; $R$, universal gas constant; and $k_{\mathrm{B}}$, Boltzmann constant. The $p^{0} / R T$ term in this equation is used to calculate $\Delta G^{\neq}$at standard state, where $p^{0}=$ 1 atm. ${ }^{8}$

Fig. 1 shows experimentally measured $\Delta G^{\neq} v s$. DFT calculated $\Delta G^{\neq}$when both are available. A good linear fit is achieved $(R=0.9285)$, suggesting that the B3LYP/6-311++G(2d,p) method and PCM solvation model are effective in predicting the degradation trend of QPs for both pathways. We also used an alternative method to calculate $\Delta G^{\neq}$via M06 ${ }^{37} / 6-311++\mathrm{G}(2 \mathrm{~d}, \mathrm{p})$ and SMD solvation model. ${ }^{38}$ However, this resulted in a worse fit $(R=0.7429$, Fig. S15 $\dagger)$. The good correlation between experimental and B3LYP/PCM calculated $\Delta G^{\neq}$values for QP cations is surprising, since for QA cations the same method usually shows a worse correlation with experiment. For example, we recently performed a similar fitting for 20 different QA cations using B3LYP/PCM method, resulting in a much worse fit with $R=$ 0.3350 . The degradation measurements were performed in different environments: a low-water environment $\left(\mathrm{CD}_{3} \mathrm{OD} / \mathrm{D}_{2} \mathrm{O}\right.$ 


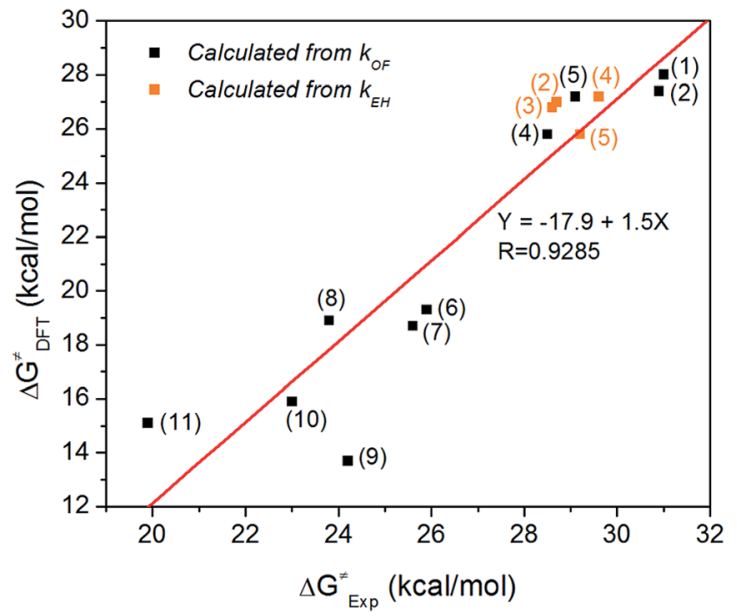

Fig. 1 Experimentally measured $\Delta G^{\neq}$vs. DFT calculated $\Delta G^{\neq}$using B3LYP/6-311++G(2d,p) method and PCM solvation model.

(5/1 vol) solution) for QPs $v s$. aqueous solution for QAs. One possible explanation for this good correlation is that the PCM implicit solvation model used in B3LYP calculations underestimated the solvation effect of water, yielding data more consistent with the measurements in the less solvated environment.

Both experimental and DFT data presented in Table 2 suggest that the oxide formation pathway usually has a lower reaction barrier than the ether hydrolysis pathway, implying that unprotected $\mathrm{P}$ atom is more vulnerable to $\mathrm{OH}^{-}$attacking than $\mathrm{OCH}_{3}$ group. In these cases, the rate determining step for the degradation is the oxide formation reaction. This is not surprising since $\mathrm{OH}^{-}$can attack the unprotected $\mathrm{P}$ atom easily via $\mathrm{P}$ atom's vacant $\mathrm{d}$ orbital. To make the reaction barrier of oxide formation higher, we have employed large steric hindrance in cations (e.g., cation (2) and cation (3)), which results in significant enhancement of $\Delta G_{\mathrm{OF}}^{\neq}$. Take cation (3) $\left(\Delta G_{\mathrm{EH}}^{\neq}=26.8 \mathrm{kcal} \mathrm{mol}^{-1}, \Delta G_{\mathrm{OF}}^{\neq}=29.6 \mathrm{kcal} \mathrm{mol}^{-1}\right)$ for example, regions near the $\mathrm{P}$ atom become very crowded, preventing $\mathrm{OH}^{-}$ from attacking the $\mathrm{P}$ atom.
Fig. 2 shows the ground state, oxide formation TS, and ether hydrolysis TS of cation (3). This cation has three phenyls and one benzyl linked to $\mathrm{P}$ atom. For the oxide formation pathway, $\mathrm{OH}^{-}$can either attack the $\mathrm{P}$ atom through the pore formed by three phenyl ligands or by two phenyls and one benzyl. Obviously, the steric effect is weaker in the latter case owing to the smaller size of $\mathrm{CH}_{2}$ group in the benzyl ligand, so that this will be the major route for $\mathrm{OH}^{-}$to attack the $\mathrm{P}$ atom (Fig. 2a). This is confirmed by DFT data: the $\Delta G_{\mathrm{OF}}^{\neq}$values for the above two routes are $33.4 \mathrm{kcal} \mathrm{mol}^{-1}$ and $29.6 \mathrm{kcal} \mathrm{mol}^{-1}$, respectively. As $\mathrm{OH}^{-}$approaches the $\mathrm{P}$ atom, the three ligands (two phenyls and one benzyl) move resembling the opening of an umbrella to accommodate the $\mathrm{OH}^{-}$(Fig. 2b). As the result, $o-\mathrm{OCH}_{3}$ on the phenyl groups will become closer to each other. The closest $\mathrm{O}-\mathrm{O}$ distance for $o-\mathrm{OCH}_{3}$ groups in Fig. 2a and b is $2.88 \AA$ and $2.81 \AA$, respectively, indicating slightly stronger steric interference in the oxide formation TS than in the ground state. For the ether hydrolysis pathway, as $\mathrm{OH}^{-}$approaches the methyl of $\mathrm{OCH}_{3}$ from the opposite direction of the bond between the methyl and the $\mathrm{O}$ atom, the three $\mathrm{H}$ atoms on methyl takes a similar umbrella flip movement (Fig. 2a and c). In this case, the increase of the steric hindrance is negligible (the $\Delta G_{\mathrm{EH}}^{\neq}$values for different cations only change slightly $\left(1-2 \mathrm{kcal} \mathrm{mol}^{-1}\right)$ due to electronic effects). Therefore, for cation (3), ether hydrolysis reaction becomes the dominant degradation pathway.

Establishing a relationship between structure and alkaline stability would greatly benefit the search for new alkali-stable QP cations. A semi-empirical formula could bypass the need for screening experimentally or running DFT calculations (some QP cations are so large that DFT calculations of all potential degradation pathways would use as many as 100000 processor hours). Our proposed formula is based on the Taft equation (eqn (2)), which describes the relationship between reaction rate constants and the electronic and steric effects for different substituents: $:^{39-41}$

$$
\log \left(\frac{k}{k_{0}}\right)=\sigma \rho+E_{\mathrm{s}} \rho_{\mathrm{s}}
$$

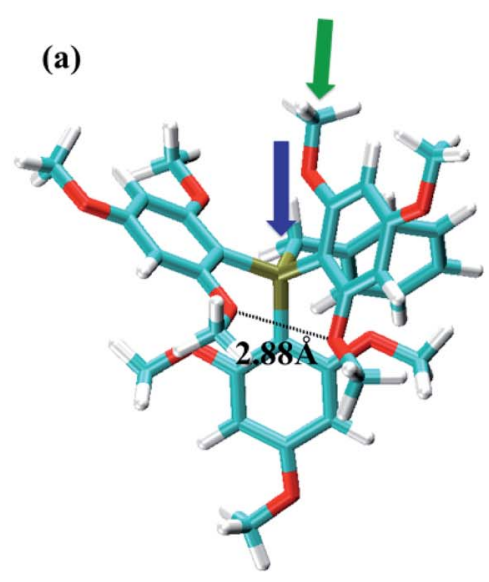

(b)

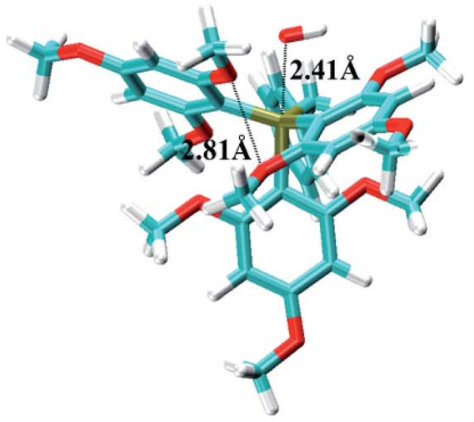

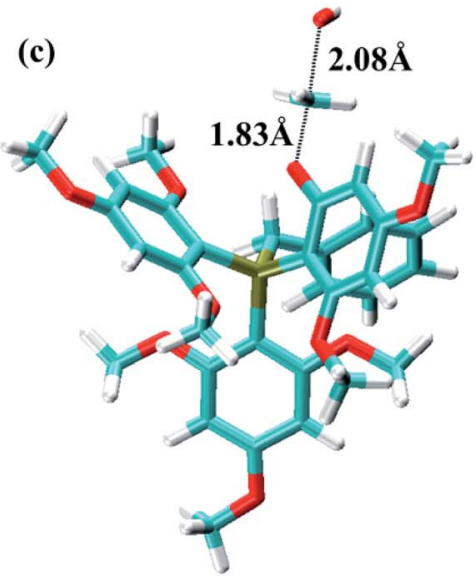

Fig. 2 (a) Ground state, (b) oxide formation TS, and (c) ether hydrolysis TS for cation (3). Color scheme: P-tan, C-cyan, O-red, and H-white. The blue and green arrows in (a) show the $\mathrm{OH}$-attack directions for the oxide formation and ether hydrolysis pathways, respectively. 


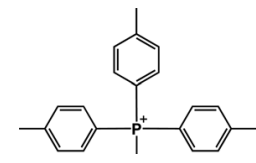

Fig. 3 Chemical structure of MTPP-(p-Me) (cation (13)).

where $k_{0}$ is the reference reaction rate of the unsubstituted reactant and $k$ is the reaction rate of a substituted reactant; $\sigma$ and $E_{\mathrm{S}}$ are the polar substituent constant and the steric substituent constant, respectively; and $\rho$ and $\rho_{\mathrm{s}}$ are the linear sensitivity factors for the electronic and steric effects, respectively. It was found that $\sigma$ can be replaced by the ${ }^{31} \mathrm{P}$ NMR chemical shifts $(\delta)$ for phosphorus compounds. ${ }^{42}$ The smaller value of $\delta$ (shift upfield) indicates stronger electron-donating ability of the substituent. According to eqn (1) and (2), $\Delta G^{\neq}$ will have a linear relationship with $\delta$ and $E_{\mathrm{s}}$ (eqn (3)):

$$
\Delta G^{\neq}=a \delta+b E_{\mathrm{s}}+c
$$

where $a, b, c$ are linear fitting constants.

The following discussion will consider only $\Delta G_{\mathrm{OF}}^{\neq}$because the ether hydrolysis pathway depends only on individual behavior of the methoxy groups, not on $\delta$ or $E_{\mathrm{s}}$. There are three types of steric effect in all the QPs studied: $o-\mathrm{CH}_{3}, o-\mathrm{OCH}_{3}$ and $\mathrm{P}-\mathrm{CH}_{2} \mathrm{C}_{6} \mathrm{H}_{5}$. The steric effect of the para-substituent is negligible due to its large distance from the P center. We estimated $E_{\mathrm{s}}$ by DFT as follows: we designed a new QP, MTPP-( $p$-Me) (cation (13)) (Fig. 3). The steric effect in cation (13) is weak so that it is very unstable experimentally. We performed a DFT calculation for the ground state of this cation and compared the free energies with its isomer, cation (8). The $\Delta G$ between two isomers is $16.5 \mathrm{kcal} \mathrm{mol}^{-1}$. By assuming that the electronic effects are similar for $p-\mathrm{CH}_{3}$ and $o-\mathrm{CH}_{3}{ }^{43}$ this energy difference can be attributed to the steric effect of the $o-\mathrm{CH}_{3}$ group.

With $E_{\mathrm{s}}=0$ for QPs with $\mathrm{P}-\mathrm{CH}_{3}$ and para-substituents (e.g., in cation (9) and cation (13)), then $E_{\mathrm{s}}=16.5$ for $o-\mathrm{CH}_{3}$. Similarly, we can calculate the $\Delta G$ values between other pairs of isomer cations. The $\Delta G$ between cation (6) and cation (9) is $8.0 \mathrm{kcal} \mathrm{mol}{ }^{-1}$, and thus, $E_{\mathrm{s}}\left(o-\mathrm{OCH}_{3}\right)=8.0$. The $\Delta G$ between cation (7) and cation (10) is $13.5 \mathrm{kcal} \mathrm{mol}^{-1}$, and the steric effect

Table $3 \delta, E_{\mathrm{s}}$, as well as experimentally measured and fitted $\Delta G_{\mathrm{OF}}^{\neq}$for the oxide formation pathway

\begin{tabular}{llcll}
\hline Cations & $\delta$ & $E_{\mathrm{S}}$ & $\begin{array}{l}\Delta G_{\mathrm{OF}, \mathrm{EXP}}^{\text {F }} \\
\left(\mathrm{kcal} \mathrm{mol}^{-1}\right)\end{array}$ & $\begin{array}{l}\Delta G_{\mathrm{OF}, \mathrm{Fitted}}^{\neq} \\
\left(\mathrm{kcal} \mathrm{mol}^{-1}\right)\end{array}$ \\
\hline$(1)$ & 6.53 & 33.0 & 31.0 & 30.9 \\
$(2)$ & -3.79 & 16.0 & 30.9 & 30.1 \\
$(4)$ & -1.84 & 16.0 & 28.5 & 29.7 \\
$(5)$ & 7.85 & 21.5 & 29.1 & 28.7 \\
$(6)$ & 20.1 & 8.0 & 25.9 & 24.0 \\
$(7)$ & 24.7 & 13.5 & 25.6 & 24.0 \\
$(8)$ & 21.7 & 16.5 & 23.8 & 25.1 \\
$(9)$ & 18.8 & 0 & 24.2 & 22.9 \\
$(10)$ & 20.8 & 5.5 & 23.0 & 23.4 \\
$(11)$ & 22.0 & 5.5 & 19.9 & 23.2
\end{tabular}

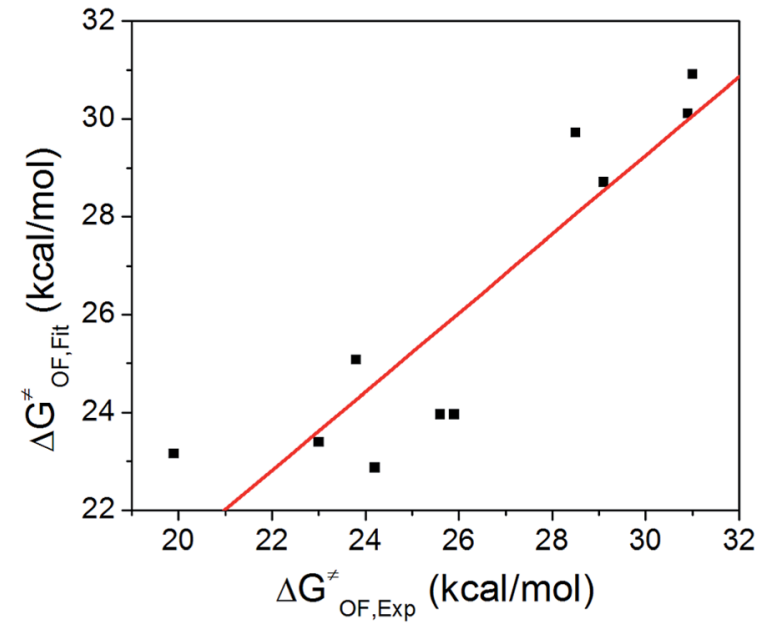

Fig. 4 Fitted vs. experimentally measured $\Delta G_{\mathrm{OF}}^{\neq}$.

is assumed to be the linear combination of $E_{\mathrm{s}}\left(0-\mathrm{OCH}_{3}\right)$ and $E_{\mathrm{s}}\left(\mathrm{P}-\mathrm{CH}_{2} \mathrm{C}_{6} \mathrm{H}_{5}\right)$, so that $E_{\mathrm{s}}\left(\mathrm{P}-\mathrm{CH}_{2} \mathrm{C}_{6} \mathrm{H}_{5}\right)=13.5-E_{\mathrm{s}}\left(o-\mathrm{OCH}_{3}\right)=$ $13.5-8.0=5.5$. Based on these parameters, we can estimate the total $E_{\mathrm{s}}$ for cations with multiple steric contributions. For example, for cation (3), $E_{\mathrm{s}}(3)=E_{\mathrm{s}}\left(\mathrm{P}-\mathrm{CH}_{2} \mathrm{C}_{6} \mathrm{H}_{5}\right)+2 \times E_{\mathrm{s}}\left(o-\mathrm{OCH}_{3}\right)$ $=5.5+2 \times 8.0=21.5$. The $E_{\mathrm{s}}$ values for cations with the oxide formation pathway are presented in Table 3 .

Based on $\delta, E_{\mathrm{s}}$, and $\Delta G_{\mathrm{OF}, \mathrm{Exp}}^{\neq}$values in Table 3 , we performed a three-dimensional linear fit to obtain $a, b, c$ (eqn (3)) using software package GNUPLOT 4.2. The fitting gives: $a=$

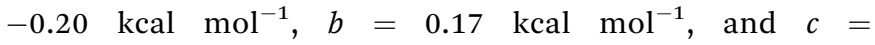
$26.6 \mathrm{kcal} \mathrm{mol}^{-1}$. We then used these values, $\delta$, and $E_{\mathrm{s}}$ to calculate $\Delta G_{\mathrm{OF} \text {,Fitting }}^{\neq}$by eqn (3) and presented the results in Table 3. Fig. 4 indicates that $\Delta G_{\mathrm{OF}, \mathrm{Exp}}^{\neq}$and $\Delta G_{\mathrm{OF}, \mathrm{Fitting}}^{\neq}$have a reasonable linear relationship $(R=0.8988)$. Thus, the stability of cations can be directly estimated by using the ${ }^{31} \mathrm{P}$ NMR chemical shift $\delta$ and the $E_{\mathrm{S}}$ deduced from the chemical structure.

\section{Conclusion}

The alkaline degradation mechanism and kinetics of a series of QP cations were studied experimentally and theoretically. B3LYP and PCM solvation model effectively predicted the degradation trend of QP cations for oxide formation and ether hydrolysis pathways. To explore the structure-stability relationship of QPs, a semi-empirical formula based on the Taft equation was established, by which alkaline stability of QP cations can be estimated from ${ }^{31} \mathrm{P}$ NMR chemical shift $\delta$ and steric parameter $E_{\mathrm{s}}$. This relationship will be valuable in searching for QP cations with improved stability and also provide insight for structure-alkaline stability prediction of other types of cations such as QA. For example, if we replace P$\mathrm{CH}_{3}$ in cation (1) (the most stable one we have) with $\mathrm{P}$ $\mathrm{CH}_{2} \mathrm{C}_{6} \mathrm{H}_{5}$, we would increase $E_{\mathrm{s}}$ by 5.5 so that the new cation may be a promising candidate to further boost alkaline stability. 


\section{Conflicts of interest}

There are no conflicts to declare.

\section{Acknowledgements}

This work is supported in part by the MURI program of the ARO under contract W911NF-10-1-0520 and the ARPA-E program of the DOE under contract DE-AR-0000009.

\section{References}

1 S. Gu, B. Xu and Y. Yan, in Annual Review of Chemical and Biomolecular Engineering, ed. J. M. Prausnitz, M. F. Doherty and R. A. Segalman, 2014, vol. 5, pp. 429-454.

2 S. Gottesfeld, D. R. Dekel, M. Page, C. Bae, Y. Yan, P. Zelenay and Y. S. Kim, J. Power Sources, 2018, 375, 170-184.

3 J. R. Varcoe, P. Atanassov, D. R. Dekel, A. M. Herring, M. A. Hickner, P. A. Kohl, A. R. Kucernak, W. E. Mustain, K. Nijmeijer, K. Scott, T. Xu and L. Zhuang, Energy Environ. Sci., 2014, 7, 3135-3191.

4 R. Borup, J. Meyers, B. Pivovar, Y. S. Kim, R. Mukundan, N. Garland, D. Myers, M. Wilson, F. Garzon, D. Wood, P. Zelenay, K. More, K. Stroh, T. Zawodzinski, J. Boncella, J. E. McGrath, M. Inaba, K. Miyatake, M. Hori, K. Ota, Z. Ogumi, S. Miyata, A. Nishikata, Z. Siroma, Y. Uchimoto, K. Yasuda, K. I. Kimijima and N. Iwashita, Chem. Rev., 2007, 107, 3904-3951.

5 J. R. Varcoe, R. C. T. Slade, G. L. Wright and Y. Chen, J. Phys. Chem. B, 2006, 110, 21041-21049.

6 S. Gu, W. Sheng, R. Cai, S. M. Alia, S. Song, K. O. Jensen and Y. Yan, Chem. Commun., 2013, 49, 131-133.

7 S. Lu, J. Pan, A. Huang, L. Zhuang and J. Lu, PNAS, 2008, 105, 20611-20614.

8 H. Long, K. Kim and B. S. Pivovar, J. Phys. Chem. C, 2012, 116, 9419-9426.

9 J. B. Edson, C. S. Macomber, B. S. Pivovar and J. M. Boncella, J. Membr. Sci., 2012, 399, 49-59.

10 G. Merle, M. Wessling and K. Nijmeijer, J. Membr. Sci., 2011, 377, 1-35.

11 S. Chempath, J. M. Boncella, L. R. Pratt, N. Henson and B. S. Pivovar, J. Phys. Chem. C, 2010, 114, 11977-11983.

12 S. Chempath, B. R. Einsla, L. R. Pratt, C. S. Macomber, J. M. Boncella, J. A. Rau and B. S. Pivovar, J. Phys. Chem. C, 2008, 112, 3179-3182.

13 C. S. Macomber, J. M. Boncella, B. S. Pivovar and J. A. Rau, J. Therm. Anal. Calorim., 2008, 93, 225-229.

14 J. R. Varcoe and R. C. T. Slade, Fuel Cells, 2005, 5, 187-200. 15 K.-D. Kreuer, Chem. Mater., 2014, 26, 361-380.
16 M. A. Hickner, A. M. Herring and E. B. Coughlin, J. Polym. Sci., Part B: Polym. Phys., 2013, 51, 1727-1735.

17 Y.-J. Wang, J. Qiao, R. Baker and J. Zhang, Chem. Soc. Rev., 2013, 42, 5768-5787.

18 A. Brouzgou, A. Podias and P. Tsiakaras, J. Appl. Electrochem., 2013, 43, 119-136.

19 H. Zhang and P. K. Shen, Chem. Soc. Rev., 2012, 41, 23822394.

20 H. Zhang and P. K. Shen, Chem. Rev., 2012, 112, 2780-2832.

21 J. Pan, C. Chen, L. Zhuang and J. Lu, Acc. Chem. Res., 2012, 45, 473-481.

22 Y. A. Elabd and M. A. Hickner, Macromolecules, 2011, 44, 111.

23 G. Couture, A. Alaaeddine, F. Boschet and B. Ameduri, Prog. Polym. Sci., 2011, 36, 1521-1557.

24 A. Serov and C. Kwak, Appl. Catal., B, 2010, 98, 1-9.

25 E. Antolini and E. R. Gonzalez, J. Power Sources, 2010, 195, 3431-3450.

26 F. Bidault, D. J. L. Brett, P. H. Middleton and N. P. Brandon, J. Power Sources, 2009, 187, 39-48.

27 T. W. Xu, J. Membr. Sci., 2005, 263, 1-29.

28 B. Zhang, B. R. Kaspar, S. Gu, J. Wang, Z. Zhuang and Y. Yan, ChemSusChem, 2016, 17, 2374-2379.

29 K. J. T. Noonan, K. M. Hugar, H. A. Kostalik, E. B. Lobkovsky, H. D. Abruna and G. W. Coates, J. Am. Chem. Soc., 2012, 134, 18161-18164.

30 S. Gu, R. Cai, T. Luo, Z. Chen, M. Sun, Y. Liu, G. He and Y. Yan, Angew. Chem., Int. Ed., 2009, 48, 6499-6502.

31 S. Gu, R. Cai, T. Luo, K. Jensen, C. Contreras and Y. Yan, Chemsuschem, 2010, 3, 555-558.

32 S. Gu, R. Cai and Y. Yan, Chem. Commun., 2011, 47, 28562858.

33 H. Long, K. Kim and B. S. Pivovar, J. Phys. Chem. C, 2012, 116, 9419-9426.

34 H. Long and B. Pivovar, J. Phys. Chem. C, 2014, 118, 98809888.

35 H. Long and B. S. Pivovar, ECS Trans., 2014, 64, 1211-1219. 36 A. D. Becke, J. Chem. Phys., 1993, 98, 5648-5652.

37 Y. Zhao and D. G. Truhlar, Theor. Chem. Acc., 2008, 120, 215241.

38 A. V. Marenich, C. J. Cramer and D. G. Truhlar, J. Phys. Chem. B, 2009, 113, 6378-6396.

39 R. W. Taft, J. Am. Chem. Soc., 1952, 74, 2729-2732.

40 R. W. Taft, J. Am. Chem. Soc., 1952, 74, 3120-3128.

41 R. W. Taft, J. Am. Chem. Soc., 1953, 75, 4538-4539.

42 C. C. Mitsch, L. D. Freedman and C. G. Moreland, J. Magn. Reson., 1971, 5, 140-144.

43 J. Shorter, Usp. Khim., 1971, 40, 2081-2101. 